\title{
INDUCIBLE NITRIC OXIDE SYNTHASE MODULATES ANGIOGENESIS IN ISCHEMIC HINDLIMB OF RAT
}

\author{
Sedigheh Nematollahi ${ }^{a}$, Mehdi Nematbakhsh ${ }^{a *}$, Shaghayegh Haghjooyjavanmard ${ }^{a}$, \\ Majid Khazaei ${ }^{a}$, Mohammad Salehi ${ }^{\mathrm{b}}$
}

\author{
a Department of Physiology, Applied Physiology Research Center, Isfahan University of Medical Sciences, Isfahan, Iran \\ ${ }^{b}$ Department of Histology, School of Medicine, Tehran University of Medical sciences, Tehran, Iran \\ e-mail:nematbakhsh@gmail.com,nematbakhsh@mui.ac.ir
}

Received: January 22, 2009; Accepted: March 15, 2009

Keywords: Angiogenesis/Hind limb ischemia/Nitric oxide/Inducible nitric oxide synthase (iNOS)/L-NIL/Hypoxic inducible factorla (HIFla)

Background: Angiogenesis plays an important role in maintaining adequate oxygen delivery, and nitric oxide (NO) is a potential regulator of angiogenesis. NO is synthesized through three isoforms of NO synthase (NOS). It is hypothesized that the NO derived from inducible NOS (iNOS) may promote survival of ischemic tissue through angiogenesis. To test this hypothesis, we investigated the effect of iNOS deficiency (by L-NIL) on angiogenesis in a hindlimb ischemia model.

Methods: Thirty-two male wistar rats randomly divided into four groups. In groups $1 \& 2$, hindlimb ischemia was induced by ligation of femoral artery and they received L-NIL and saline respectively. The animals in groups 3 and 4 also received L-NIL and saline respectively without surgical procedure. After 21 days, the serum concentration of nitrite, capillary density and expression of HIF $1 \alpha$ were determined.

Results: Serum nitrite levels were significantly lower in L-NIL groups $(p<0.05)$. The capillary density in group 1 (ischemia + L-NIL) was significantly different from group 2 (ischemia + saline); group 1: $360.33 \pm 77.02$, group 2: 549 $\left.\pm 81.85 / \mathrm{mm}^{2}, \mathrm{p}<0.05\right)$.In addition, expression of HIF $1 \alpha$ was significantly increased in ischemic groups $(p<0.05)$.

Conclusion: Selective inhibition of iNOS by L-NIL inhibits angiogenesis in a hindlimb ischemic rat model. In addition, ischemia induces expression of HIF1 $\alpha$ in hypoxic tissue.

\section{INTRODUCTION}

Angiogenesis is the postnatal process whereby an existing microvascular network is expanded ${ }^{1}$. In adults, angiogenesis occurs physiologically in wound healing and in the menstrual cycle. It may also occur in pathological conditions $^{2,3}$. In general, angiogenesis requires several important processes including dissolution of matrix, endothelial cell proliferation and migration, and organization into tubes, followed by lumen formation.

Nitric oxide (NO) is a free radical, produced from L-arginine by NO synthase (NOS), and it is an important regulator of angiogenesis ${ }^{4}$. There are three different forms of NOS; neural NOS (nNOS, NOS-I), endothelial NOS (eNOS, NOS-III), and inducible NOS (iNOS, NOS-II) ${ }^{5}$. NO can induce angiogenesis in vivo ${ }^{6}$, and it also has a proangiogenic effect ${ }^{5}$. eNOS modulates angiogenesis in response to ischemia ${ }^{7}$, and it plays a predominant role in vascular endothelial growth factor (VEGF)-induced angiogenesis. Although iNOS appears to have a small but additive effect on angiogenesis ${ }^{8}$, but it has been subjected of various studies. iNOS is expressed in severe corneal alkali burns and inhibits neovascularization ${ }^{9}$. For proangiogenic effect of iNOS in capillary formation, it is demonstrated that iNOS and VEGF are over expressed in ameloblas- tomas, and both promote tumoral growth, invasion and metastasis ${ }^{10}$. iNOS also appears to play a key role in tumor angiogenesis in head and neck cancer ${ }^{11}$, and the NO derived from iNOS promotes survival of ischemic tissue through angiogenesis in a skin flap model ${ }^{12}$.

The angiogenesis depended iNOS in pathological and physiological conditions may have different mechanisms. The regulation of angiogenesis by hypoxia is an important component of homeostatic control ${ }^{13}$. The major factor which responds to hypoxia is hypoxia-inducible factor-1 (HIF-1) including two subunits of alpha (HIF-1 $\alpha$ ) and beta (HIF-1 $\beta$ ). HIF-1 $\alpha$ modulates transcriptional control of several genes such as VEGF, eNOS and angiopoietin- $2^{14}$. Hindlimb ischemia is a valid model for investigating in-vivo angiogenesis. To explain the role of eNOS on angiogenesis, Akasaki et al induced angiogenesis via eNOS using thermal therapy in mice with hindlimb ischemia $^{15}$, and angiogenesis was also induced by injection of animal eNOS plasmid and human eNOS gene transfer in ischemic hindlimb model ${ }^{16,17}$, but the role of iNOS in angiogenesis has not been explained completely. In this study we tested the role of iNOS on angiogenesis in a rat model of hindlimb ischemia. HIF- $1 \alpha$ expression in ischemic muscles was also evaluated. 


\section{MATERIALS AND METHODS}

This study was reviewed and approved by the Ethics Committee of Isfahan University of Medical Sciences.

Experimental design: Thirty-two male wistar rats $(170 \pm 20 \mathrm{~g})$ were kept in a temperature controlled room and allowed free access to food and water. Animals were randomly divided into four groups. Groups $1(\mathrm{n}=10)$ and $2(\mathrm{n}=9)$ were subjected to induced hindlimb ischemia experimentally. No surgical procedure for hindlimb ischemia was induced in groups $3(\mathrm{n}=7)$ and 4 $(\mathrm{n}=5)$. The rats in groups $1 \& 3$ received N6-iminoethylL-lysine (L-NIL) and the other groups received an equal volume of saline.

Rat ischemic hindlimb model: Rats were anesthetized with xylazine $(2 \mathrm{mg} / \mathrm{kg}$; ip), followed by ketamine $(100 \mathrm{mg} / \mathrm{kg}$; ip) for unilateral femoral artery ligation. The left femoral artery was isolated .Then the entire femoral artery and all its major branches were completely ligated with 3-00 surgical silk ${ }^{7,18}$.As a consequence, blood flow to the ischemic limb becomes completely dependent upon collateral vessels issuing from the internal iliac artery. The wounds were sutured, and the animals were allowed to recover. All animals appeared fully recovered within 12 hour with no signs of tissue necrosis. Antibiotic (cefazoline, $40 \mathrm{mg} / \mathrm{kg}$ ) was injected in the single daily dose for 3days after surgery.

L-NIL administration: L-NIL (partially-selective iNOS inhibitor) is 23 fold selective for iNOS versus nNOS and 49 fold selective for iNOS versus eNOS ${ }^{19}$. L-NIL (Cayman Corp., Michigan, USA) was administrated 24 hours before the surgery and continued by the end of experiment ( 21 days after surgery). L-NIL was dissolved in saline and injected $(3 / \mathrm{mg} / \mathrm{kg} / \mathrm{day} \text {; ip })^{20}$.

Sample preparation and NO assay in serum: Blood samples were taken from all animals before and after the study. The serums were stored at $-70{ }^{\circ} \mathrm{C}$ for NO measurement. NO was determined by the evaluation of its stable oxidation product (nitrite, NI) by using the Griess reaction (Promega Corp., Madison, USA).

Tissue preparation and Immunohistochemistry (IHC): By the end of experiment, the animals were killed with an overdose of anesthetic drug. For immunohistochemistry, gastrocnemius muscles from ischemic and non ischemic left limbs were immediately fixed in formalin and paraffin-embedded block were prepared. The 5- $\mu \mathrm{m}$ thick sections were used for immunohistochemical analysis. Identification of endothelial cells was performed by staining for endothelial cell adhesion molecule-1 (PECAM-1 or CD31) using a mouse monoclonal antibody directed against rat CD31 (Abcam, Cambridge, UK). Determination of HIF-1 $\alpha$ expression was performed using a mouse monoclonal antibody directed against rat HIF-1 $\alpha$ (Abcam, Cambridge, UK). In brief; the sections were incubated in $3 \%$ hydrogen peroxide to block endogenous peroxide activity. The slides were treated with antigen retrieval solution ( $0.05 \%$ trypsin) at $37{ }^{\circ} \mathrm{C}$ for $20 \mathrm{~min}$. To prevent nonspecific antibody binding; sections were preincubated for $45 \mathrm{~min}$ in PBS containing $10 \%$ goat serum. The sections were incubated with the primary antibodies directed against either CD31 or HIF-1 $\alpha$ at appropriate dilutions 1 hours at $37^{\circ} \mathrm{C}$, and then rinsed for 15 min with PBS followed by incubation with secondary antibody (Rabbit polyclonal to mouse IgG, Abcam,

Table 1. The serum nitrite concentrations $(\mu \mathrm{mol} / 1)$ in four groups of experiments.

\begin{tabular}{|l|r|c|c|}
\hline \multicolumn{1}{|c|}{ group } & n & before & after \\
\hline ischemia + L-NIL & 10 & $12.15 \pm 2.98$ & $9.21 \pm 1.11^{*}$ \\
\hline ischemia +saline & 9 & $12.26 \pm 1.74$ & $11 \pm 4$ \\
\hline L-NIL & 7 & $12.52 \pm 2.96$ & $9.43 \pm 0.89^{*}$ \\
\hline saline & 5 & $10.05 \pm 1.37$ & $11.29 \pm 1.42$ \\
\hline
\end{tabular}

* Significant difference from before $(\mathrm{p}<0.05)$.

Table 2. The capillary density and capillary/muscle fiber ratio $(\mathrm{C}: \mathrm{F})$ in four groups of experiments.

\begin{tabular}{|l|c|c|c|c|}
\hline \multicolumn{1}{|c|}{ group } & $\mathbf{n}$ & $\begin{array}{c}\text { Capillary Density } \\
\left(/ \mathbf{m m}^{2}\right)\end{array}$ & $\begin{array}{c}\text { Fiber } \\
\left(/ \mathbf{m m}^{2}\right)\end{array}$ & C : F \\
\hline ischemia + L-NIL & 5 & $360.33 \pm 77.02$ & $385.33 \pm 78.08$ & $0.93 \pm 0.04$ \\
\hline ischemia +saline & 5 & $549 \pm 81.85 *$ & $468.4 \pm 116.74 *$ & $1.2 \pm 0.22 *$ \\
\hline L-NIL & 3 & $314 \pm 34.21$ & $357.66 \pm 36.55$ & $0.87 \pm 0.038$ \\
\hline saline & 3 & $293.33 \pm 6.50$ & $323.66 \pm 12.66$ & $0.9 \pm 0.01$ \\
\hline
\end{tabular}

* Significant difference from other groups $(\mathrm{p}<0.05)$ 
Cambridge, UK) for 1 hours at $37{ }^{\circ} \mathrm{C}$. Again the sections were rinsed with PBS and incubated with diaminobenzidine and counterstained with hematoxylin. Negative control slides were prepared by substituting PBS for CD31 and HIF- $1 \alpha$ staining.

Analysis of capillary density: Capillary densities in both ischemic and nonischemic limbs were analyzed for specific evidence of neovascularity. Endothelial cells positively stained with CD31 were counted under light microscope. Twenty different microscopic fields on three different sections from each animal were counted. Capillaries were counted under a $40 \times$ objective to determine the capillary density (mean number of capillaries $/ \mathrm{mm}^{2}$ ). To ensure that capillary density was not overestimated as a result of muscle atrophy or underestimated because of interstitial edema, the capillary/muscle fiber $\operatorname{ratio}(\mathrm{C}: \mathrm{F})$ also was determined for each histological section. All histological analyses were performed by two blinded observer.

Analysis of HIF-1a expression: Expression of HIF-1 $\alpha$ was determined by two independent observers .The immunohistochemical result for HIF- $\alpha$ was graded as follows; zero: no staining, 1: nuclear staining in less than $1 \%$ of cells, 2: nuclear staining in 1-10\% of cells and/or with weak cytoplasmic staining, 3: nuclear staining in 10-50\% of cells and/or with distinct cytoplasmic staining, and 4:
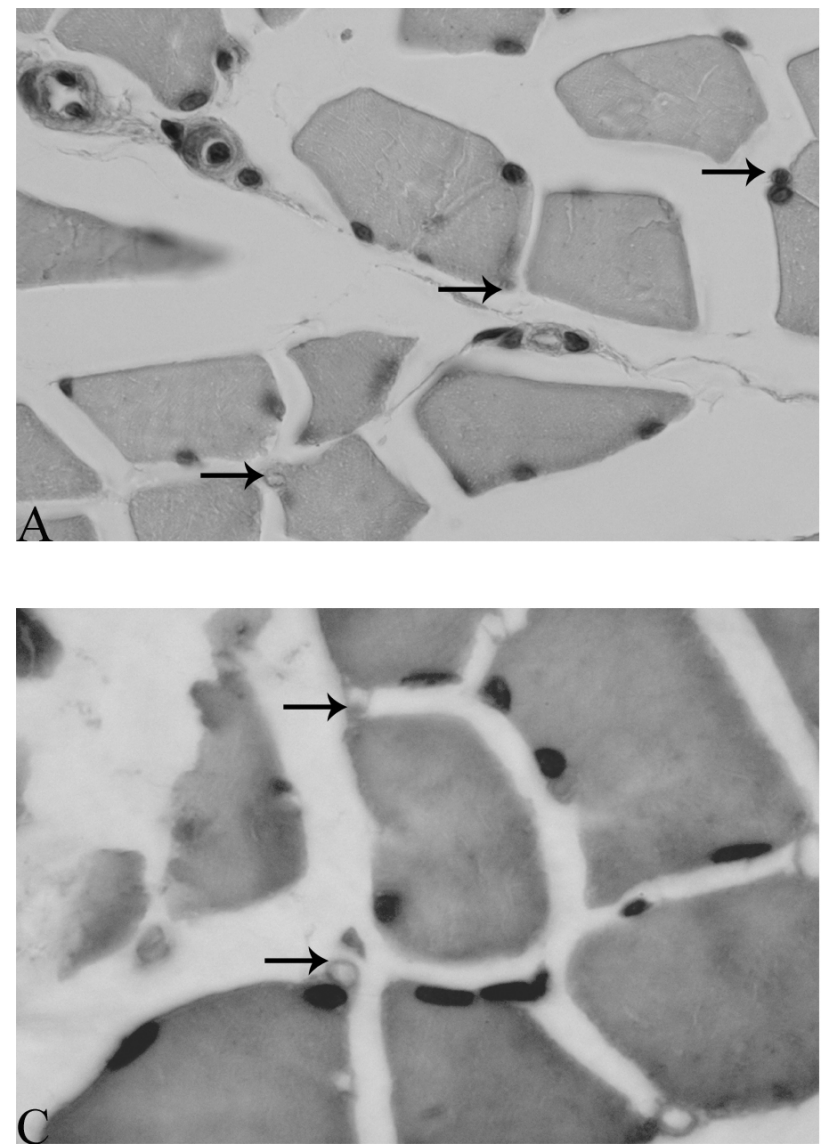

nuclear staining in more than $50 \%$ of cells and/or with strong cytoplasmic staining ${ }^{21}$.

Statistical analysis: All results are expressed as mean \pm SD. Statistical significance was evaluated using ANOVA for comparisons of capillary density and serum NI concentration between four groups. Comparison of serum NI concentration before and after study was performed using paired Student's $t$ test. The difference in expression of HIF- $1 \alpha$ between groups was tested using the Kruskalwallis test. A p value less than 0.05 was interpreted as statistically significant.

\section{RESULTS}

Serum NI concentration measurement: The results indicate that, serum NI concentrations in groups land 3 were significantly decreased ( $p<0.05$; Table 1$)$ after 3 weeks of L-NIL treatment. In contrast serum NI concentration in groups 2 and 4 (L-NIL untreated) did not differ significantly (Table 1 ).

Histological determination of capillary density: The data for capillary density and capillary/muscle fiber ratio in the gastrocnemius muscles in 4 experimental animal groups are shown in Table 2. L-NIL (in group 1) significantly reduced capillary density (angiogenesis) compared
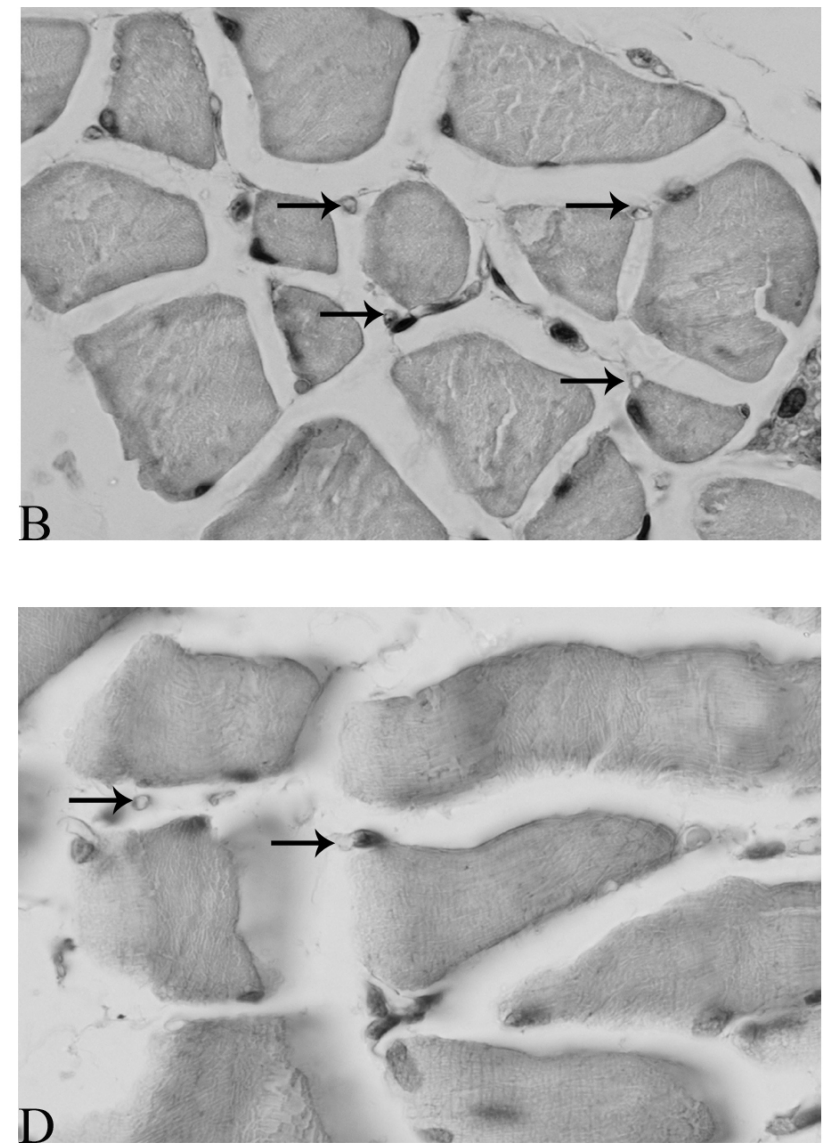

Fig. 1. Immunostaining of ischemic hindlimb tissue. Identification of endothelial cells was performed by staining for endothelial cell adhesion molecule-1 (PECAM-1 or CD31) using a mouse monoclonal antibody directed against rat CD31. The endothelial cells positively stained with CD31(capillary density) in group 1(A) markedly reduced compared to group 2(B). (C and D) are capillary densities in groups 3 and 4. 

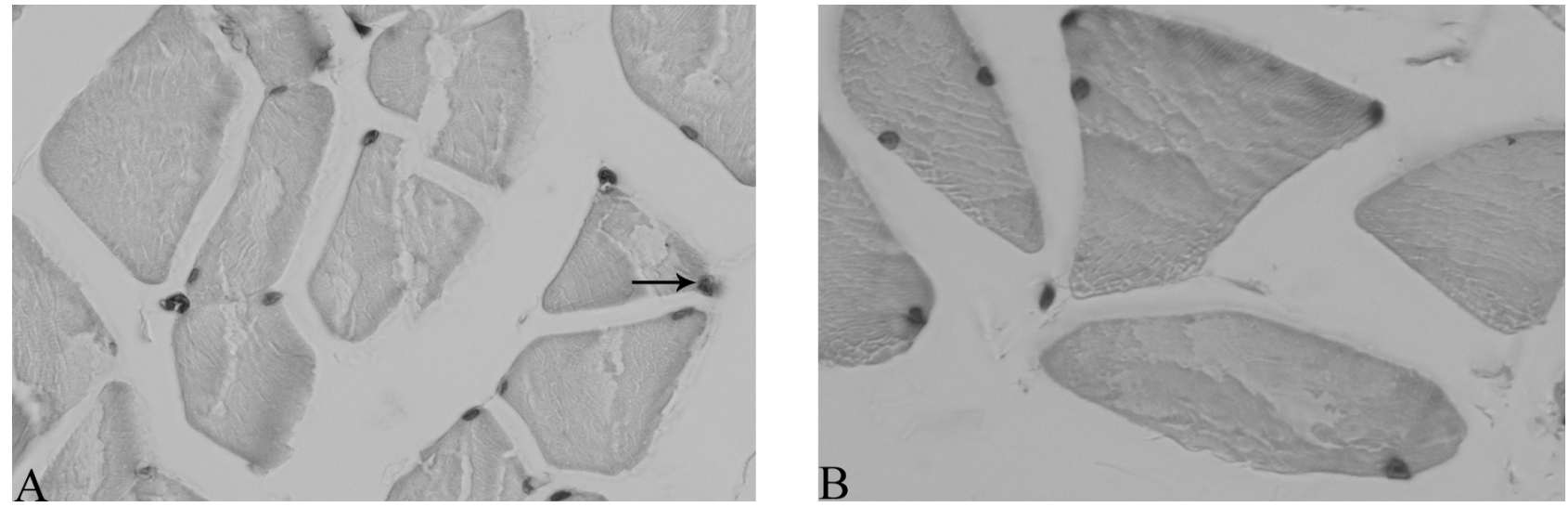

Fig. 2. The Expression of HIF-1 $\alpha$ in (A) ischemic group and (B) non ischemic group.

with group 2 ( $\mathrm{p}<0.05$; Fig. 1). Capillary/muscle fiber ratio was also higher in group 2 than group $1(\mathrm{p}<0.05)$.

Expression of HIF-1 $\alpha$ : HIF-1 $\alpha$ expression was recognized through a nuclear staining of positive cells. There was no expression of this protein in nonischemic limb samples (Fig. 2). In contrast, histological analysis revealed that, amounts of HIF- $1 \alpha$ were increased significantly in skeletal muscle of the ischemic hindlimb of groups 1and 2 (Fig. 2). The statistical analysis indicates no significant difference in HIF-1a expression between the groups of 1 and $2(2 \pm 1$ vs $1.4 \pm 0.54)$.

\section{DISCUSSION}

In this study, we assessed the effect of iNOS inhibition on the process of capillary proliferation (angiogenesis), and the results indicate that iNOS is essential for angiogenesis in a model of ischemic tissues. It is clear that a large number of molecules are involved in the angiogenic cascade $^{22}$. The regulation of capillary growth by NO is complex due to both angiogenic and antiangiogenic effects of $\mathrm{NO}^{6,23,24}$. Moreover, the role of NOS isoforms in angiogenesis is controversial. It has been shown that eNOS (for angiogenesis in ischemic tissues in vivo) and iNOS (for angiogenesis in hypoxic mouse hearts in vitro) are essential ${ }^{4,7}$. iNOS inhibits neovascularization ${ }^{9}$, and selective iNOS inhibitor can reduce the rate of growth of solid tumors in mice ${ }^{25}$. However, iNOS expression has been more extensively described in tumour angiogenesis where it was found to be increased and correlated with vascularization ${ }^{26}$. Among the NO metabolites, NI is a major oxidative metabolite suggesting it is an indicator of NOS activity ${ }^{27}$, and L-NIL is a selective iNOS inhibitor ${ }^{8}$. Other studies have reported that iNOS activity decreased by L-NIL treatment ${ }^{8,28,29}$. Production of NO by iNOS requires dimerization ${ }^{30}$, and primary mechanism of the iNOS inactivation by L-NIL is heme alteration and $\operatorname{loss}^{31}$. Pipili-Synetos et al, inhibited chick chorioallantoic membrane (CAM) angiogenesis by a transcriptional activator of $\mathrm{iNOS}^{32}$ while others demonstrated that iNOS has effects on angiogenesis ${ }^{8}$. Hypoxia is known to induce several genes including VEGF and iNOS, and iNOS is potentially involved in VEGF-induced angiogenesis ${ }^{33}$. It seems that NO derived from iNOS is a critical regulatory molecule for physiologic angiogenesis in response to ischemia. However this role may vary depending on the nature of the angiogenic stimulus and the tissue involved $^{8,18}$.

The histological analysis showed that the amount HIF- $1 \alpha$ was increased in skeletal muscle of the ischemic hindlimb. HIF-1 $\alpha$ was identified and purified as a nuclear factor that induces in hypoxic cells ${ }^{13}$. Hypoxia results in loss of prolyl hydroxylation of HIF- $1 \alpha$ and a consequent reduction both in the level of HIF-1 $\alpha$ ubiquitination and in its degradation by the proteasome, leading to increase in HIF- $1 \alpha$ abundance and HIF-mediated transcriptional responses $^{34}$. Some studies indicate that constitutively active HIF- $1 \alpha$ or inhibition of HIF- $1 \alpha$ inactivation induces angiogenesis and causes differences in HIF- $1 \alpha$ expression between ischemic groups ${ }^{14,35,36}$. Whereas there is no procedure for inhibition of HIF-1 $\alpha$ degradation in our study, we found no difference in HIF- $1 \alpha$ expression between ischemic groups. Our observation for HIF-1 $\alpha$ is similar to Pampin et $\mathrm{al}^{37}$ who suggested that the angiogenic effects of HIF- $1 \alpha$ are limited to regions of terminal small vessels in the myocardial tissue.

In conclusion, this study indicates that iNOS inhibition significantly reduces angiogenesis in ischemic tissue. Thus, modulation of iNOS activity is a promising strategy for altering angiogenesis in response to hypoxia in vivo.

\section{ACKNOWLEDGMENT}

This study was supported by Isfahan University of Medical sciences, Isfahan, Iran. The authors wish to thank H. Sadeghi for skillful assistance.

\section{REFERENCES}

1. Hudlicka $\mathrm{O}$, Brown $\mathrm{M} \&$ Egginton $\mathrm{S}$. Angiogenesis in skeletal and cardiac muscle. Physiol Rev 1992; 72: 369-417.

2. Sandra Liekens, Erik De Clercq, Johan Neyts. Angiogenesis: regu- 
lators and clinical applications. Biochemical Pharmacology 2001; 61: $253-70$

3. Nematbakhsh M, Ghadesi M, Hosseinbalam M, Khazaei M, Gharagozlo M, Dashti G, Rajabi P, Rafieian S. Oestrogen promotes coronary angiogenesis even under normoxic conditions. Basic Clin Pharmacol Toxicol. 2008;103(3):273-7.

4. Namba T, Koike H, Murakami K, Aoki M, Makino H, Hashiya N, Ogihara T, Kaneda Y, Kohno M, Morishita R. Angiogenesis induced by endothelial nitric oxide synthase gene through vascular endothelial growth factor expression in a rat hindlimb ischemia model.Circulation 2003;108(18):2250-7.

5. Sennlaub F, Courtois Y, Goureau O. Inducible nitric oxide synthase mediates the change from retinal to vitreal neovascularization in ischemic retinopathy. J Clin Invest 2001;107(6):717-25.

6. Ziche M, Morbidelli L, Masini E, Amerini S, Granger HJ, Maggi CA, Geppetti P, Ledda F. Nitric oxide mediates angiogenesis invivo and endothelial cell growth and migration in vitro promoted by substanceP. J. Clin. Invest 1994; 94:2036-44.

7. Murohara T, Asahara T, Silver M, Bauters C, Masuda H, Kalka C, Kearney M, Chen D, Symes JF, Fishman MC, Huang PL, Isner JM. Nitric oxide synthase modulates angiogenesis in response to tissue ischemia. J Clin Invest 1998; 101(11):2567-78.

8. Fukumura D, Gohongi T, Kadambi A, Izumi Y, Ang J, Yun CO, Buerk DG, Huang PL, Jain RK. Predominant role of endothelial nitric oxide synthase in vascular endothelial growth factor-induced angiogenesis and vascular permeability. Proc Natl Acad Sci U S A 2001;98(5):2604-9.

9. Sennlaub F, Courtois Y, Goureau O. Nitric oxide synthase-II is expressed in severe corneal alkali burns and inhibits neovascularization. Invest ophthalmol Vis Sci 1999;40(12):2773-9.

10. Chen Wl, Ouyang KX, Li HG, Huang ZQ, Li JS, Wang JG. Expression of Inducible Nitric Oxide Synthase andVascular Endothelial Growth Factor in Ameloblastoma. J Craniofacial Surgery 2009; 20 (1): 171-5.

11. Gallo O, Masini E, Morbidelli L, Franchi A, Fini-Storchi I, Vergari WA, Ziche M. Role of nitric oxide in angiogenesis and tumor progression in head and neck cancer. J Natl Cancer Inst 1998;90(8):587-96.

12. Kane AJ, Barker JE, Mitchell GM, Theile DR, Romero R, Messina A, Wagh M, Fraulin FO, Morrison WA, Stewart AG. Inducible nitric oxide synthase (iNOS) activity promotes ischaemic skin flap survival. Br J Pharmacol 2001; 132(8):1631-8.

13. Hirota K, Semenza GL. Regulation of angiogenesis by hypoxiainducible factor 1.Crit Rev Oncol Hematol 2006;59(1):15-26.

14. Milkiewicz M, Pugh CW, Egginton S. Inhibition of endogenous HIF inactivation induces angiogenesis in ischaemic skeletal muscles of mice. J Physiol $2004 ; 560(\mathrm{Pt} 1): 21-6$

15. Akasaki Y, Miyata M, Eto H, Shirasawa T, Hamada N, Ikeda Y, Biro S, Otsuji Y, Tei C. Repeated thermal therapy up-regulates endothelial nitric oxide synthase and augments angiogenesis in a mouse model of hindlimb ischemia. Circ J. 2006;70(4):463-70.

16. Namba T, Koike H, Murakami K, Aoki M, Makino H, Hashiya N, Ogihara T, Kaneda Y, Kohno M, Morishita R. Angiogenesis induced by endothelial nitric oxide synthase gene through vascular endothelial growth factor expression in a rat hindlimb ischemia model. Circulation. 2003;108(18):2250-7.

17. Smith RS Jr, Lin KF, Agata J, Chao L, Chao J. Human endothelial nitric oxide synthase gene delivery promotes angiogenesis in a rat model of hindlimb ischemia. Arterioscler Thromb Vasc Biol. 2002 Aug 1;22(8):1279-85.

18. Lloyd PG, Yang HT, Terjung RL. Arteriogenesis and angiogenesis in rat ischemic hindlimb: role of nitric oxide Am J Physiol Heart Circ Physiol. 200;281(6):H2528-38.

19. Alderton WK, Cooper CE, Knowles RG. Nitric oxide synthases: structure, function and inhibition Biochem J. 2001;357(Pt 3):593615 .
20. McCartney-Francis NL, Song X, Mizel DE, Wahl SM. Selective inhibition of inducible nitric oxide synthase exacerbates erosive joint disease J Immunol. 2001;166(4):2734-40.

21. Zhong H, De Marzo AM, Laughner E, Lim M, Hilton DA, Zagzag D, Buechler P, Isaacs WB, Semenza GL, Simons JW. Over expression of hypoxia-inducible factor 1alpha in common human cancers and their metastases. Cancer Res 1999;59(22):5830-5.

22. Milkiewicz M, Ispanovic E, Doyle JL, Haas TL. Regulators of angiogenesis and strategies for their therapeutic manipulation. Int $\mathrm{J}$ Biochem Cell Biol 2006;38(3):333-57.

23. Lau YT, Ma WC. Nitric oxide inhibits migration of culturedendothelial cells. Biochem. Biophys. Res. Commun 1996; 221:670-4.

24. RayChaudhury A, Frischer H, Malik AB. Inhibition of endothelial cell proliferation and bFGF-induced phenotypic modulation by nitric oxide. J Cell Biochem 1996 ;63(2):125-34.

25. Thomsen LL, Scott JM, Topley P, Knowles RG, Keerie AJ, Frend AJ. Selective inhibition of inducible nitric oxide synthase inhibits tumor growth in vivo: studies with $1400 \mathrm{~W}$, a novel inhibitor. Cancer Res 1997;57(15):3300-4.

26. Donnini S, Ziche M. Constitutive and inducible nitric oxide synthase: role in angiogenesis.Antioxid Redox Signal 2002;4(5):817-23.

27. Rhodes P, Leone AM, Francis PL, Struthers AD, Moncada S, Rhodes PM The L-argenin: nitric oxide pathway is the major source of plasma nitrite in fasted humans. Biochem Biophys Res Comm 1995; 209(2): 590-6.

28. Ostendorf T, Van Roeyen C, Westenfeld R, Gawlik A, Kitahara M, De Heer E, Kerjaschki D, Floege J, Ketteler M. Inducible nitric oxide synthase derived nitric oxide promotes glomerular angiogenesis via upregulation of vascular egf receptors. $\mathbf{J}$ am soc Nephrol. 2003; 15(9): 2307-19.

29. Stenger S, Donhauser N, Thüring H, Röllinghoff M, Bogdan C. Reactivation of latent leishmaniasis by inhibition of inducible nitric oxide synthase. J Exp Med 1996; 183(4): 1501-14.

30. Xie QW, Leung M, Fuortes M, Sassa S, Nathan C. Complementation analysis of mutants of nitric oxide synthase reveals that the active site requires two hemes. Proc Natl Acad Sci U S A 1996;93(10):4891-6.

31. Bryk R, Wolff DJ. Mechanism of inducible nitric oxide synthase inactivation by aminoguanidine and L-N6-(1-iminoethyl)lysine. Biochemistry. 1998; 37(14):4844-52.

32. Pipili-Synetos E, Kritikou S, Papadimitriou E, Athanassiadou A, Flordellis C, Maragoudakis ME. Nitric oxide synthase expression, enzyme activity and NO production during angiogenesis in the chick chorioallantoic membrane. Br J Pharmacol. 2000;129(1):207. 13 .

33. Kroll J. VEGF-A induces expression of eNOS and iNOS in endothelial cells via VEGF receptor-2 (KDR). Biochem Biophys Res Commun 1998; 252: 743-6.

34. Ichihara S, Yamada Y, Ichihara G, Nakajima T, Li P, Kondo T, Gonzalez FJ, Murohara T. A role for the aryl hydrocarbon receptor in regulation of ischemia-induced angiogenesis. Arterioscler Thromb Vasc Biol 2007;27(6):1297-304.

35. Vincent KA, Shyu KG, Luo Y, Magner M, Tio RA, Jiang C, Goldberg MA, Akita GY, Gregory RJ, Isner JM. Angiogenesis is induced in a rabbit model of hindlimb ischemia by naked DNA encoding an HIF-1alpha/VP16 hybrid transcription factor. Circulation 2000;102(18):2255-61.

36. Patel TH, Kimura H, Weiss CR, Semenza GL, Hofmann LV. Constitutively active HIF-1alpha improves perfusion and arterial remodeling in an endovascular model of limb ischemia. Cardiovasc Res 2005;68(1):144-54.

37. Blanco Pampín J, García Rivero SA, Otero Cepeda XL, Vázquez Boquete A, Forteza Vila J, Hinojal Fonseca R. Immunohistochemical expression of HIF-1 $\alpha$ in response to early myocardial ischemia. J Forensic sci. 2006; 51(1): 120-4. 
